\title{
Dispositivos de memória e narrativas do espaço urbano: cartografias flutuantes no tempo e espaço
}

\author{
Regina Helena Alves da Silva, Claudia Graça da Fonseca, \\ Juliana de Oliveira Rocha Franco, Pedro da Silva Marra e Milene Migliano Gonzaga
}

\section{Resumo}

0 texto discute as possibilidades de leitura do espaço urbano a partir da interação comunicativa de pessoas comuns nas ruas do Hipercentro da cidade de Belo Horizonte. Para estudar este fenômeno, procurou-se entender a ação dos sujeitos sobre o tempo-espaço da cidade como interações comunicativas. Ao agir sobre os lugares, no cotidiano, os sujeitos atribuem significados aos espaços, transformando a sua significação ou apenas atualizando os significados circulantes. 0 material empírico que serviu de base ao estudo foi coletado através de derivas cartográficas, estratégia de abordagem do espaço urbano inspirada nas derivas dos situacionistas.

\section{Palavras-chave}

Interações comunicativas. Cidade.

Territórios urbanos.

Regina Helena Alves da Silva | regina.helena@gmail.com

Doutora em História Social pela Universidade de São Paulo - USP. Professora do Programa de Pós-Graduação em Comunicação da Universidade Federal de Minas Gerais - UFMG.

\section{Claudia Graça da Fonseca | cgraca@fafich.ufmg.br} Doutora em Comunicação Social pela UFMG.

\section{Juliana de Oliveira Rocha Franco | judorf@gmail.com \\ Mestre em Comunicação Social pela UFMG.}

\section{Pedro Silva Marra | pedromarra@gmail.com}

Mestre em Comunicação Social pela UFMG.

Milene Migliano Gonzaga | milenemigliano@gmail.com Mestranda em Comunicação Social pela UFMG.

\section{Introdução}

Historicamente, a cartografia é produzida pelo Homem desde tempos muito remotos e associa duas formas de conhecimento sobre 0 espaço: a ciência e a arte. Como antiga prática humana de reflexão sobre o espaço, é difícil determinar quando surgem as primeiras cartografias, mas é certo, todavia, que uma idéia de lugar a ser conhecido e reconhecido está sempre anotada nestas representações, sejam lugares ocupados, imaginados ou inventados. As primeiras cartas e mapas produzidos pelo homem traziam uma marcada intenção de organização do espaço, também presente nas mais atuais cartografias.

Mas toda organização espacial tem uma escala particular que deve ser acessada apenas em seus próprios contextos. A cosmologia, reconhecida como uma das primeiras cartografias, resulta de um entendimento cíclico do tempo em que o presente - tempo dos homens, das coisas, da natureza e da vida propriamente dita - tempo de alternâncias, é determinado de forma transcendente por alguma entidade divina inalcançável e, mais tarde, pela antiga ciência. É 
essa determinação que se busca incessantemente "representar" na cartografia cosmológica, uma idéia totalizadora, uma escala universal.

Entretanto, foi no século XIX que a idéia de representação do espaço em mapas, gráficos e outros produtos do fazer cartográfico passou a ser atravessada, de forma imperativa, por uma determinação técnica e científica da realidade mesma do espaço representado. A cartografia moderna inscreve-se como uma técnica de levantamentos político-militares em um contexto colonial e imperialista, dispensando uma atenção particular à escala urbana. 0 desenho urbano representado no papel procurou sobrepor-se às lógicas e dinâmicas sociais. Os estudos, as plantas e os projetos que então formalizaram o planejamento urbanístico das cidades, desta forma, inscreveram a produção cartográfica moderna em um quadro de forte idealização do espaço ocupado, tal e qual se observava na produção cartográfica antiga (HISSA, 1998).

É preciso ressaltar, contudo, que a cartografia, os fazeres cartográficos e seus produtos, estão diretamente associados a uma forma de organização do conhecimento sobre 0 espaço, a uma maneira de conceber, representar e interpretar o mundo, a uma forma de articular saberes e poderes, isto é, a uma configuração imaginária construída a partir de uma perspectiva que privilegia determinados elementos e processos em detrimento de outros. Nossa proposta é sublinhar estes aspectos e, no mesmo movimento, contrariar a visão essencialista e totalizadora do mundo buscando os processos de enunciação do cotidiano da cidade e suas dinâmicas. Colocando em relevo as contradições que emergem das articulações estabelecidas entre 0 oficial e 0 extra-oficial, das negociações e das formas de uso e ocupação do espaço, o que se pretende é observar a diversidade de sentidos produzidos e em produção no espaço e ampliar a legibilidade, tornando visíveis lugares localizados à margem dos processos culturais, sociais e políticos hegemônicos (ABRAMS; HALL, 2006; COSGROVE, 1999; HARMON, 2004).

Este é 0 olhar que orientou a construção e 0 desenvolvimento do projeto Cartografias de Sentidos do Hipercentro de Belo Horizonte: produzir posicionamentos críticos diante de uma série de imagens sobre essa região da cidade, ao longo de sua história, realizando recortes e combinações discursivas que pudessem estimular outros processos de significação e apresentando imagens conflitantes e redes de convergência desse espaço, tensionando os imaginários configurados histórica e culturalmente.

A escolha do Hipercentro como objeto de estudos parte da importância desta região na dinâmica social do município de Belo Horizonte. Tanto o desenho da cidade quanto a concentração de diferentes tipos de atividades e serviços marcam a passagem de grande parte da população belohorizontina e as mais diferentes formas de uso e de ocupação de suas ruas, praças e equipamentos, 
produzindo uma pluralidade de sentidos ora mais ou menos articulados, ora mais ou menos tensionados.

\section{Derivas cartográficas: construindo uma metodologia de campo}

Nossos esforços se concentraram em formas de captar a cidade pelo olhar de quem caminha pelo espaço. A equipe de pesquisadores do Cartografias dos Sentidos saiu a campo pelas ruas do Hipercentro realizando anotações sobre o espaço urbano em seu cotidiano, utilizando as novas tecnologias de comunicação e informação para efetuar registros, e também buscando informações em arquivos e na internet. A forma de abordagem do espaço urbano foi chamada de derivas cartográficas, em referência às derivas situacionistas. Durante o processo, buscamos descrever e refletir sobre as metodologias utilizadas no reconhecimento de nosso campo e, em conseqüência, na construção de nosso saber acerca do espaço. Como pudemos perceber, estas metodologias não extinguem a figura do pesquisador observador, mas, ao contrário permitem que ele mude o foco de seu olhar. Ao invés de observar os fenômenos sociais por si, buscamos perceber de que forma estes constroem significados para os habitantes - passantes e ficantes - da cidade. 0 pesquisador não se exclui do conjunto, participando também destes processos. Esta postura possibilitou uma imersão na experiência de uma cidade viva. As relações entre as pessoas no espaço urbano, bem como a ocupação da cidade e os usos e apropriações das ruas, quarteirões, etc. nos interessaram como os meios com que os habitantes de uma cidade vivenciam-na, atribuindo sentidos múltiplos a esta vivência.

As formas de registrar nossas experiências e observações em mapas não abandonaram completamente os princípios cartográficos de localização do indivíduo no espaço, mas buscaram fazê-lo sem cristalizar a diversidade da cidade. Procuramos narrá-las ao invés de descrevê-las em suportes físico-simbólicos.

A possibilidade encontrada para a realização de tal tarefa foi a de transformar nossas projeções cartográficas em dispositivos de memória. 0s registros não buscavam esgotar todas as possibilidades do centro da cidade. Este procedimento acabaria por enrijecer nossos mapas. Denominamos de dispositivos de memória ferramentas que nos ajudam a lembrar. Para tanto, nos apropriamos dos mecanismos de funcionamento da memória humana, que é lacunar e realiza seu trabalho por meio da tentativa de conexão dos fragmentos de tempo nela presentes. Não se tratou de uma tentativa de fixação da totalidade de uma memória em um suporte físico. 0 dispositivo de memória que nos interessa é aquele que não elimina a atividade daquele que 0 acessa, mas, pelo contrário, estimula o funcionamento da memória do observador por meio da disponibilização de fragmentos da história da cidade. Cabe ao indivíduo que utiliza nossos mapas complementar 
o que falta, por meio da atividade de sua própria memória e imaginação. Nossa cartografia configura-se, portanto, através de mecanismos de rememoração coletiva, promovendo, desta forma, a narração do espaço urbano.

A metodologia de derivas cartográficas nos permitiu produzir um conhecimento acerca do espaço urbano. Para produzir os registros - que são a base para os mapas que configuram a cartografia de sentidos - precisamos sempre estar atentos aos conceitos que determinamos como princípios orientadores da pesquisa.

Dependendo da forma como procedermos em sua confecção, poderemos ocultar a dinâmica da cidade e dos conhecimentos que havíamos apreendido. Para que isso não ocorresse, as projeções cartográficas constituídas acerca do espaço urbano deveriam abandonar seu caráter descritivo e adotar uma perspectiva narrativa, a fim de transformar esses registros em dispositivos de memória capazes de estimular a atividade de seu observador, que se responsabilizaria por "completar" os fragmentos oferecidos pelos mapas acessados com lembranças próprias.

Para realizar esta transposição do conhecimento para os dispositivos de memória, foi preciso encontrar formas de registrar nossa experiência de pesquisa em suportes que permitissem 0 seu acesso a outras pessoas. Nossos procedimentos de pesquisa nos possibilitaram o registro do espaço ocupado através da fotografia, das paisagens sonoras e do vídeo. Esta alternativa não foi adotada sem uma reflexão crítica acerca das implicações da utilização de aparelhos técnicos no registro do mundo sensível e de sua experiência. Afinal, o mundo da vida nos mostra muito bem como estas novas tecnologias constituem a tentação de tudo registrar, haja vista a enorme quantidade de estímulos sonoros, visuais e textuais dispostos cotidianamente na cidade, nos meios de comunicação de massa, etc. (BLEECKER; KNOWLTON, 2008; GALLOWAY; WARD, 2006; GRAHAM; MARVIN, 1997; WEST, 2005).

Este fenômeno pode implicar uma acomodação da memória humana, já que não precisaríamos mais nos preocupar em lembrar ou esquecer, afinal tudo estaria fixado em suportes produzidos pelo aparelho técnico. É claro que não damos conta de registrar tudo. Mas é possível que se caia no engano de acreditar que tudo está registrado. Com este registro total, não há lugar para a memória e seu processo de lembrar a partir das lacunas formada através do tempo. 0 que nos resta são meras cenas, que insistimos em chamar de instantâneos, e que fixam um passado pálido. Sobra uma lembrança cristalizada no tempo; sua única relação com o presente é o fato de não mais existir daquela forma.

Como então utilizar a técnica no registro da cidade a fim de transformá-la em dispositivo de memória e não em seu "arquivo"? Para buscar respostas para tal pergunta, nos apoiamos nos escritos do filósofo de origem tcheca radicado no Brasil Vilém Flusser (2002). De acordo com seu 
livro Filosofia da Caixa Preta, os meios técnicos de registro caracterizam-se como aparelhos técnicos regidos por programas localizados em seu interior e inacessíveis, ou incompreensíveis para seus usuários; caixas pretas, onde somente é possível ver seu input e seu output, o que entra e 0 que sai. Ao aparelho caberia realizar todo 0 processo de fixação da realidade sensível em suporte de registro, a partir do que o usuário determina o que entrará pelo seu input - a saber, não só o objeto a ser registrado, mas também as categorias que 0 aparelho utiliza para realizar 0 registro. Assim, por exemplo, na tomada de uma fotografia, o usuário escolhe o que será fotografado, o enquadramento do objeto, a abertura do obturador da máquina fotográfica e 0 tempo de exposição para realização da fotografia. Influem ainda no processo condições externas ligadas ao acaso, como: se 0 objeto a ser fotografado se mexe, se há variação de luminosidade durante o registro, etc. Sob esta perspectiva, registrar configura-se como um processo complexo de transformação do que ocorre na realidade sensível em cena, onde se relacionam usuário e aparelho técnico, relação sujeita ao acaso do momento em que o registro é realizado.

Olhando mais de perto para a relação e seus termos, parece-nos, em um primeiro momento, que 0 usuário leva vantagem sobre 0 aparelho técnico na relação que determina a confecção de um registro técnico. Tal impressão logo se desfaz, no entanto, quando olhamos mais de perto para a natureza do programa que rege o funcionamento do aparelho, fator este que, como já esclarecido, permanece inacessível ao usuário: se 0 aparelho é regido pelo programa, este determina 0 universo de registros possíveis a serem realizados por aquele aparelho, e, por conseguinte, pelo usuário. Por mais vasto que seja o programa, ele não consegue realizar um registro que nele não esteja previamente inscrito. Cada registro se torna, portanto, um ponto de vista da realidade sensível. Uma conseqüência de tal fenômeno é a impossibilidade de realização de toda e qualquer intenção do usuário - esta está limitada pela potência do programa.

Os softwares não programam somente os aparelhos, eles podem ao longo do tempo acabar por formatar também a sensibilidade do usuário. À medida que realiza registros, o usuário vai aos poucos esgotando as potencialidades do aparelho. Por meio da comparação do input com o output, o usuário pode compreender 0 funcionamento do programa do aparelho técnico, passa a entender como fazer para realizar certos registros e utiliza este conhecimento para produzi-los. Quando o programa chega perto de seu esgotamento, produz, cada vez mais freqüentemente, os mesmos registros. A capacidade de invenção do usuário fica limitada e seu comportamento ao realizar registros torna-se programado. No processo, muitas vezes estimulado por uma vontade de realizar novos registros, já bastante improváveis, diversas outras conseqüências podem ocorrer. Em um primeiro momento, 0 usuário pode perder a 
referência do real e passar a perceber a realidade apenas por meio da mediação dos aparelhos técnicos. Como resultado, o que se configurava como transformação de processos pode passar a ser entendido como criação de instantâneos - pequenos fragmentos da realidade sensível caracterizados pela sua relatividade frente a outros registros de mesma natureza.

Com o intuito de se driblar tais dificuldades na constituição de uma cartografia que utilize recursos técnicos em sua confecção e não se pretenda totalizante, decidimo-nos por procedimentos que aumentassem a participação do acaso na confecção dos registros realizados. Optamos pela realização de paisagens sonoras na captação de sons pela cidade e de planos-sequência na gravação de imagens em movimento. Se 0 ato de ligar a câmera ou gravador de som no início da caminhada pelo centro de Belo Horizonte, por um lado limita a intenção do usuário do aparelho, por outro possibilita que 0 acaso tenha maior influência na realização dos registros. 0 resultado é uma maior variedade de materiais sonoros e visuais, mais condizentes com a diversidade de usos e apropriações de um espaço como o Hipercentro. Tais procedimentos também parecem mostrar de forma mais adequada e simples 0 caráter fragmentário e relativo dos registros técnicos.

\section{Derivas: cartografias flutuantes no tempo e espaço}

Para se discutir a rua do Hipercentro de Belo Horizonte e as dinâmicas que nela têm lugar, um aspecto a se considerar é a sua complexidade, marcada, por um lado, pela natureza do objeto que se tem em mãos e, por outro, pelo desafio lançado pela proposta deste estudo. Mergulhamos no cotidiano da cidade para estudar seus produtos, fluxos e apropriações nem sempre visíveis, mas que animam e reconfiguram a sua imagem imediata ou institucionalizada. Não pretendíamos esgotar esta multiplicidade, cristalizando as dinâmicas, mas nos apropriar de recortes e momentos que falam dessa diversidade em sua interação cotidiana e histórica.

Para os Situacionistas, a deriva era mais uma prática do que uma teoria, "[...] a experiência consistia em interpretar aspectos diferentes ou fragmentos da cidade simultaneamente, fragmentos que só podem ser vistos sucessivamente, da mesma forma que existe pessoas que nunca viram certas partes da cidade." (LEFEBVRE, 1983 [documento eletrônico]). Para nós a idéia de ampliação da noção de derivas passou pela interpretação conjunta destes aspectos e fragmentos e pela possibilidade de compartilhamento da experiência através da disponibilização de imagens capturadas durante 0 caminhar.

0 uso do espaço está vinculado aos ritmos de vida. Então temos aqui uma noção de ritmo de vida, ou mesmo, de ritmo social. A partir da observação de comportamentos individuais, podemos identificar unidades espaço-temporais 
como expressões justapostas ou sobrepostas sobre um mesmo espaço, e/ou marcação de espaços por grupos ou conjuntos de habitantes.

Nesta perspectiva, o espaço se constitui como objeto social, ou seja, os ritmos de vida devem ser analisados em sua dimensão social para que possamos qualificar os usos do espaço.

Bernard Lepetit chama a atenção para a questão de que o espaço urbano sempre escapa a intencionalidade funcional de quem 0 concebe (apud DOSSE, 2003, p. 280). Ele tem a potencialidade de reunir dimensões, tanto materiais quanto imateriais, de ontem e de hoje, que concordam e discordam entre si. Ao mesmo tempo em que o lugar urbano está no presente por completo ele também é composto por muitos tempos, ou seja, se apropria dos tempos/espaços antigos segundo novas normas. Mas o sentido social associado a ele nunca é levado a cabo de forma idêntica e se refere sempre a uma prática presente. Isso significa que não se pode estudar a cidade como algo inerte, coisificado para sempre pela ciência.

Marcel Roncayolo é quem primeiro vai dizer que a cidade mais do que um conceito de análise aparece como uma categoria da prática social (CIDADE, 1990). A cidade nunca é absolutamente sincrônica: 0 tecido urbano, o comportamento dos citadinos, as políticas de planificação urbanística, econômica ou social desenvolvem-se segundo cronologias diferentes. Mas, ao mesmo tempo, a cidade está inteira no presente. Ou melhor, ela é inteiramente presentificada por atores sociais nos quais se apóia toda a carga temporal.

Entender a cidade como um espaço vivido é pensá-la como um espaço cultural no sentido mais amplo deste termo: um espaço do movimento, da diferença, da multiplicidade, da hibridação, do conhecimento, da subversão e da liberdade. Nesta abordagem é fundamental trabalhar com o que temos chamado de conceitos de movimento. A perspectiva teórica apresentada por Lepetit (2001), seguindo o historiador alemão Reinhart Koselleck, que relaciona as práticas e modos de fazer aos tempos históricos da vida social, nos traz uma outra maneira de se pensar a complexidade urbana e a articulação da experiência dos sujeitos individuais e coletivos. A articulação das experiências do tempo passado vem constituindo um espaço de experiência que é atualizado no tempo presente ao se realizarem as práticas culturais. Assim, teríamos no passado uma constelação de possibilidades de escritura para o presente histórico, objetivando o horizonte de expectativa no tempo futuro em alguma medida já estabelecido. Ao materializar uma mensagem no presente instantâneo, os sujeitos estariam acessando o campo de experiências realizadas no tempo passado, a fim de obter sucesso na comunicação pretendida, ou seja, para atingir seu horizonte de expectativa.

Para Koselleck (2007, p. 17) "o tempo histórico está associado à ação social e política, a homens concretos que agem e sofrem as conseqüências 
de suas ações, a suas instituições e organizações."

Ao estudar estes homens concretos, os

sentidos de temporalidade se estabelecem de outra maneira: o presente contém e constrói a experiência passada e as expectativas futuras. Segundo o autor, a experiência é um passado presente cujos acontecimentos são incorporados e podem ser lembrados.

As experiências são moldadas por um horizonte de expectativas que se refere a uma temporalidade futura. A expectativa é o futuro feito presente, ainda não experimentado mas que pode ser descoberto. A ação humana se produz neste lugar de interseção no presente onde o passado é espaço de experiência e 0 futuro horizonte de expectativas, este é o lugar vivo da cultura.

Neste lugar, a experiência humana incorpora vivências próprias e a de outros que lhe foram transmitidas. 0 passado então pode se condensar ou expandir-se de acordo com a forma como estas experiências são incorporadas. Assim, teríamos no passado uma constelação de possibilidades de escritura para o presente histórico, objetivando o horizonte de expectativa no tempo futuro em alguma medida já estabelecido.

Segundo Vera Telles,

A cidade é um campo de práticas, para lembrar aqui novamente a sugestão de Roncayolo, então as evidências empíricas que indicadores e cartografias nos entregam podem e devem ser entendidas como pontos de cristalização de práticas e processos, como pontos de con- densação de tempos sociais e temporalidades urbanas, experiência social sedimentada e história incorporada (Bourdieu) que será preciso reativar para 0 deciframento dos sentidos e direções das evoluções recentes, das tensões e fricções que atravessam as realidades urbanas. (TELLES, 2006, p. 59)

Nas derivas pela cidade, procuramos explorar uma prática de escritura que se apóia no deslocamento constante e, consciente da nossa própria posição, do nosso olhar. Esta forma de perceber a cidade é mais que uma abordagem das coisas, é uma prática de escritura ambulante, um gênero aberto à complexidade multidimensional de distintas situações.

Essa prática de escrituras traz para 0 caminhar os mapas, os guias e os planos não mais como instrumentos que orientam e ordenam as experiências do passante em ruas desconhecidas. Estes documentos de orientação deslocam essas experiências e ocupam seu lugar, como textos, como representações que se oferecem ao olhar do leitor.

Não se trata de ler um mapa da cidade em plena cidade para que possamos nos orientar nela. A cidade passa a ser um lugar de aprendizagem no sentido benjaminiano (KOHAN, 2004): um lugar de ensinar um modo de olhar e de ler. Aqui a pedagogia sobre a cidade se baseia antes de tudo em uma aprendizagem perceptiva, que tem a ver mais com a perda do que com a acumulação de saberes, mais com 0 esquecimento do que com a memória. 
Escolhemos o centro da cidade de Belo

Horizonte no momento em que a região passa por profundas intervenções urbanas.

Processos de revitalização e requalificação dos seus espaços transformam velozmente usos e apropriações. No processo do projeto Cartografias, mais do que capturar um certo estranhamento dos habitantes com a cidade em transformação, estamos propondo a construção de uma modalidade perceptiva para a cidade. Uma coisa é a cidade objetivamente transformada pelo impacto da modernização, outra é a transformação da cidade por meio de certos mecanismos da percepção, da memória da experiência do sujeito.

Estamos, portanto, propondo uma cartografia com flutuantes coordenadas espaciais e temporais onde 0 conjunto de sentimentos, percepções, desejos e necessidades construído sobre a base das práticas e atividades desenvolvidas nos espaços cotidianos conforma múltiplos significados de sentidos de pertencimento.

Aqui a comunicação não se estabelece em uma experiência urbana dada com sentido prefigurado de passado longínquo e fundador e um futuro determinado e inalcançável. Ao contrário da cidade dos projetos de intervenção que prometem um novo espaço que tem uma missão de futuro no mundo urbano capitalista, temos uma cidade do presente, da radicalidade que vem da tensão entre 0 campo da experiência e 0 horizonte da expectativa. Uma cidade de múltiplos espaços e temporalidades, uma cidade não linear, com possibilidades de construtividades relacionais.

Isso se torna possível quando entendemos 0 espaço como um produto de inter-relações, como a esfera de possibilidade da existência da multiplicidade sempre em processo.

Espaços possibilitam interação e comunicação entre pessoas que se conhecem e que não. Conversações, saudações, frases intercambiadas para perguntar ou pedir algo, manifestações de afetividades, contato visual, olhares, estranhamentos, etc., são algumas das formas de interação e comunicação observadas. Assim, na construção de nossas cartografias flutuantes, o espaço é aberto porque é o lugar onde "há sempre conexões ainda por serem feitas, justaposições ainda a desabrochar em interação, relações que podem ou não ser realizadas."

(MASSEY, 2008, p. 32)

Esta noção pressupõe um espaço de relações múltiplas entendidas a partir de uma construtividade relacional: aqui, as relações são compreendidas como práticas encaixadas. Não como práticas que se sobrepõem, dão continuidade ou evoluem no tempo e no espaço. São práticas que se juntam, colidem, organizam, compõem, participam, desviam, enfim são múltiplas possibilidades de conformação de um todo que nunca se completa, que não tem definição de limites, apenas extensões de fronteiras. 


\section{Uma proposta de análise: paisagem, ambiência e situação}

Uma das propostas para construção dos mapas narrativos constitui-se em torno da análise dos usos das ruas a partir das noções de paisagem, ambiência e situação comunicacionais. Estas noções permitiram uma leitura da cidade e das possibilidades comunicativas de seus espaços públicos. Existem direcionamentos, conformações que são ditados por uma ordem espacial hegemônica (cidade capitalista pós-industrial).

Na rua abrem-se as fronteiras dos territórios flexíveis com estas conformações. Isto se expressa nas ambiências e paisagens.

A paisagem comunicacional exige um ponto de vista que relaciona tudo que a compõe: os sujeitos que vivem ali, trabalham, freqüentam ou apenas passam as fachadas dos edifícios, o comercio, a sinalização, os acontecimentos. Assim, qualquer componente a ser trabalhado não pode ser tomado ou compreendido em separado, ele existe e funciona sempre em relação ao conjunto no qual está situado.

A idéia de se pensar a paisagem por um viés comunicacional tem como objetivo analisar os aspectos relacionais que traduzem a experiência de sujeitos comuns em relação ao espaço. Uma paisagem é vista aqui como resultante dos diversos significados circulantes nela e até fora dela. Nela se cruzam diversos processos que dizem respeito às regulações, aos acontecimentos, à memória, à história de um lugar. Assim, uma paisagem do ponto de vista comunicacional é composta de edifícios, ruas, marcas e signos impressos neles e também pelo material simbólico que circula nela e sobre ela. Uma paisagem compõe-se da experiência dos homens que a freqüentam, que já freqüentaram e daqueles que se relacionam com ela. Os usos cotidianos do espaço são a porta de entrada para o estudo da configuração de uma paisagem.

0 sentido de paisagem não é dado simplesmente pelo que ocorre nela num momento, mas também pelo que está na memória dos homens sobre aquele lugar. 0 imaterial da paisagem se relaciona com o que acontece no espaço e acrescenta significados que não estão visíveis. Ela abriga várias ambiências, mas não é a sua somatória. Uma praça, por exemplo, a Praça Sete no Hipercentro, é uma paisagem mesmo não tendo mais uma configuração física de praça. 0 seu sentido se constitui a partir do que acontece nas suas ambiências, atravessado pela memória de seus freqüentadores e dos habitantes da cidade.

0 sentido da paisagem é afetado não só pelo visual, mas também pelos sons e cheiros. Mais ainda, na forma de seus edifícios, ruas, mobiliários e sinais e ela expressa e atualiza as relações da sociedade na qual ela se situa espacial e temporalmente. A paisagem guarda em si uma potência de significação. Seus elementos e características podem se combinar a partir das relações que são estabelecidas nela e com ela. 
Uma paisagem não é um sistema fechado. Suas fronteiras não são definidas e ela freqüentemente afeta os seus arredores e os elementos próximos costumam ser contaminados por ela.

A ambiência pensada por um viés comunicacional engloba todos os estímulos que um determinado lugar da cidade oferece e recebe dos sujeitos que a freqüentam. Em uma ambiência, o mobiliário urbano, os sons e as placas afetam os sujeitos que passam por ali, que podem ter consciência ou não dessa afetação. Ao mesmo tempo as ambiências são suscetíveis às marcas intencionais ou não que os sujeitos imprimem nelas. A ambiência urbana cria uma atmosfera própria, o que remete à etimologia da palavra (ambiance em francês = atmosfera que envolve pessoa ou coisa). $\mathrm{Na}$ arquitetura, a ambiência tem um sentido de intencionalidade, é um espaço concebido para criar um meio físico e estético.

Na ambiência urbana, pensada a partir da comunicação, não existe uma intencionalidade, mas várias que se sobrepõem e que acabam resultando num processo complexo que é a produção de sentido sobre um espaço. Os usos cotidianos, múltiplos, criam a ambiência. Para esta produção de sentido podem contribuir elementos acidentais que afetam a ambiência indiretamente.

As ambiências urbanas tendem à estabilidade, mas podem ser intermitentes. São compostas de seres animados e inanimados que comunicam 0 tempo todo. As ambiências são resultantes dos usos que se faz de um determinado espaço da cidade, nas diversas temporalidades. Elas tendem a conservar traços de memória. A banca de jornais ou um ponto de ônibus podem criar uma ambiência comunicacional. As ambiências têm uma dimensão acontecimental. A ambiência está contida na paisagem e relaciona-se com ela. Uma banca de jornal situada na Praça Sete diferenciase de outra que se localiza perto da Rodoviária. No entanto, elas afetam o espaço em que estão situadas. Elas também se afetam mutuamente formando uma das várias redes locais que ligam as paisagens na cidade.

As ambiências abrigam as situações que são interações entre sujeitos, onde a comunicação acontece. As interações podem se dar em copresença ou com marcas deixadas pelos sujeitos nos diferentes momentos. Cabe aqui uma aproximação com a idéia situacionista, não no sentido de revolucionar o cotidiano, mas na idéia de explorar possibilidades dos lugares. Nas situações, nas interações comunicativas estão os germes das possibilidades. Nelas esboça-se a participação na construção de uma cidade comum através das possibilidades de troca, de convivência com os outros com quem se compartilha o tempo e o espaço. As situações são acontecimentos na paisagem.

Dentre a pluralidade de situações experimentadas durante as derivas, encontramos diversas práticas comunicativas dos sujeitos comuns disponibilizadas na cidade. Ao vivenciar o espaço urbano, os sujeitos passam, esperam, trabalham, 
se encontram, constituindo relações sociais.

Entre as relações estabelecidas nas cidades, muitas se desenvolvem a partir das demandas de comunicação: interações face a face, sinalização de trânsito, pregões dos ambulantes, discursos em palanques. Durante a pesquisa, encontramos gestos significantes que se materializam como inscrições, colagens e desenhos nos muros, tapumes, grades de proteção, caixas de luz e de telefone no centro da cidade, que denominamos diálogos públicos. Estes gestos produzem relações de comunicação entre os que percorrem a cidade a pé, pois caminhar pela cidade é interpenetrar territórios diversos daqueles que a vista do alto permite. 0 caminhante "se arrisca, cruzando umbrais, e, assim fazendo, ordena diferenças, constrói sentidos, posiciona-se." (ARANTES, 2000, p. 119).

Por meio de seqüências de ações e gestos significativos, os diálogos públicos evidenciam a potência da cidade como suporte, ao mesmo tempo em que revela sua eminente capacidade comunicativa frente à interculturalidade em contato e negociação, em acordos ou dissonâncias. Os diálogos públicos se constituem na cidade continuamente, buscando e estabelecendo uma comunicação que não tem lugar instituído e, nesse movimento, (re)inventam outras sociabilidades urbanas possíveis; são práticas culturais que colocam em relação sujeitos diversos mas que, ao co-experienciar o mesmo espaço urbano, compartilham algo e por isso demandam e produzem formas de visibilizar opiniões e informações, tácita e taticamente.

\section{Conclusões: sistemas de encaixe, espaço de negociação}

0 trabalho que estamos desenvolvendo no projeto traz o desafio de buscar conceitos e formas de abordagem que podem dar conta de um espaço sempre em construção, de uma sociabilidade em movimento. A experiência urbana se dá no trânsito dos sujeitos pelo espaço, e as relações são marcadas por essa transitoriedade. Ao mesmo tempo é preciso não perder 0 gesto quase invisível dos sujeitos que inscrevem sua marca simbólica neste espaço em mutação. É preciso colocar este gesto em relevo, tirá-lo da invisibilidade em meio ao excesso de marcas e expressões que povoam o espaço urbano. É importante destacar o gesto de apropriação do espaço pelos indivíduos no cotidiano e neste gesto vislumbrar o germe da participação que constrói e transforma a cidade.

Nossa proposta é abrir a possibilidade de se pensar os fenômenos do cotidiano urbano em sua instabilidade e fragmentação, sem, contudo perder de vista sua importância como arranjos de sentidos que, para além da fragmentação, permitem aos homens significar os diversos espaços que compõem a cidade. Estes arranjos integram o conjunto de imagens circulantes sobre a cidade e, portanto, participam da construção das mediações que nos permitem habitar, viver, posicionar, reconhecer e sermos reconhecidos na cidade. Assim, a dimensão temporal, ou das 
múltiplas temporalidades tornou-se fundamental. Os usos do espaço são condicionados pelos ritmos da cidade. Alain Tarrius (2000) fala em ritmos sociais, identificando assim práticas coletivas generalizadas em uma cidade ou específicas de uma parte da população, como expressões justapostas, ocorrendo em tempos diversos em um mesmo espaço. Existem também dimensões espaço-temporais das diversas movimentações dos sujeitos, sejam eles fluxos migratórios, sejam eles deslocamentos nas cidades como expressões daquilo que ele chama de territórios circulantes. A noção de territorialidade como processo espaço-temporal possibilita redimensionar fenômenos encarados apenas como fragmentários e inseri-los na dinâmica da cidade.

A partir disto, o espaço urbano se constitui em objeto social e os ritmos de vida devem ser analisados em sua dimensão social. Um espaço na rua, um ponto na calçada transforma-se em algo que não está previsto na sua construção e isto não estará sempre visível. 0 uso compartilhado que sujeitos e grupos fazem do espaço/tempo da cidade não está necessariamente fixado no espaço, embora possa se relacionar com ele de maneira regular. Abordados desta maneira, os usos são movimentos que instituem e apagam sentidos; territorializam e desterritorializam espaços na cidade.

Temos uma distinção entre produção, criação ativa da própria realidade e uma resposta reativa (consumista) a esta. Uma possibilidade de criar experimentações que tornem o cotidiano urbano, tido como um lugar da fragmentação e da banalidade, em um espaço da revelação, da crítica e da transformação. Onde esse fazer cotidiano instaure um espaço público que é utilizado de diferentes maneiras ao longo do tempo, que não se caracteriza nem pela estabilidade, nem pela continuidade.

Um espaço de negociação, de disputa tanto do ponto de vista material quanto discursivo. Ele é constituído, utilizado e negociado por grupos heterogêneos e públicos parciais. 0 encontro e a negociação contínua de diferentes interesses e concepções de valores, as atribuições de significados - às vezes contraditórios constituem o que chamamos de espaços públicos.

No centro de Belo Horizonte o espaço urbano como espaço público tem sido usado com cada vez menos freqüência como um espaço de sociabilidade. De um lado, as ruas do centro da cidade são consideradas na perspectiva da política urbana um lugar de passagem. Por outro lado, a rua é mais que um espaço de passagem, de deslocamento de um ponto ao outro. Ela é o lugar das negociações diárias por varias coisas e principalmente pelo direito de circular. Na rua são estabelecidos vínculos, que tornam a cidade cada vez mais íntima. Este é o espaço do domínio de referências geográficas e sociais, de absorção de um conhecimento específico, uma espécie de "saber de rua", percepções de corporalidades, gestos, olhares, que criam performances 
interativas e, portanto, relações sociais das mais diversas (FRANGELLA, 2005).

Se pensarmos o espaço como multiplicidade (MASSEY, 2008), promover a captura de significados só é possível a partir da compreensão de que o espaço urbano não é mais prioritariamente usado para a circulação e para 0 deslocamento: existe a possibilidade de transformação de espaços de fluxos em espaço de lugares; as ruas além de permitir a circulação da cidade se tornam espaços públicos de sociabilidade.

0 que se percebeu nesse percurso, foi que olhar para os processos de significação em curso na cidade, através dos vários mapeamentos, não nos permite falar em uma unidade do espaço urbano, que é fragmentado e múltiplo. No entanto, ao percorrê-lo, torna-se possível enxergar as possibilidades de ligações entre seus lugares. As observações das ruas permitiram ver nos fragmentos de usos e de significações algumas conexões que aproximam os espaços. 0 mapeamento a partir da interação de registros digitais faz com que se possa enxergar a cidade como um conjunto diferenciado formado por partes homogêneas e diversas.

Pensar a cidade, a partir da comunicação nas ruas, nos permite vê-la como algo que é formado por um sistema de encaixes complexos. Ao usar o espaço, os indivíduos fazem escolhas, costuram fragmentos. 0s lugares resultam de pequenos movimentos de produção de sentido coletivo. Não se pode falar em fronteiras definidas, nem em distinções muito claras entre as diversas áreas, mas ao longo do tempo a cidade vai-se deixando marcar aqui e ali por estes movimentos, tornando disponíveis suas possibilidades de significação. Como se fosse um jogo de peças de encaixes no qual se tem disponível uma mistura de espaços, objetos, edifícios e tempos, os lugares suscitam conexões múltiplas.

\section{Referências bibliográficas:}

ABRAMS, Janet; HALL, Peter (ed.). Else/where: mapping - new cartographies of networks and territories. Minneapolis: University of Minnesota Design Institute, 2006.

ARANTES, Antônio Augusto. Paisagens paulistanas: transformações no espaço público. Campinas: Unicamp; São Paulo: Imprensa Oficial, 2000. BENJAMIN, Walter. Rua de mão única. Obras escolhidas II. São Paulo: Brasiliense, 2000.

BLEECKER, Julian; KNOWLTON, Jeff. Locative media: a brief bibliography and taxonomy of gps-enabled locative media. Disponível em: <leoalmanac.org/ journal/Vol_14/lea_v14_n03-04/jbleecker.asp >. Acesso em: 17 fev. 2008 .

CERTEAU, Michel de. A invenção do cotidiano: 1. Artes do fazer. 4. ed. Petrópolis: Vozes, 1999.

CIDADE. Einaudi. 1996.

COSGROVE, Denis (ed.) Mappings. London: Reaktion Books, 1999 .

DOSSE, François. Michel de Certeau. México: Universidad Iberoamerica, 2003.

FERRARA, Lucrecia D'Aléssio. Cidade: fixos e fluxos. In: Simpósio Interfaces das Representações Urbanas 
em Tempos de Globalização, Bauru: SescSP-Bauru e Faac, 2005. Disponível em: <http://www.sescsp.org.br/ sesc/Conferencias/subindex.cfm?Referencia=3687\&Par amEnd=4>. Acesso em: 23 maio 2006.

FLUSSER, Vílem. Filosofia da caixa preta: ensaios para uma futura filosofia da fotografia. Rio de Janeiro: Relume Dumará, 2002.

FOUCAULT. Michel. Microfísica do poder. Rio de Janeiro: Graal. 2000.

FRANGELLA, Simone Miziara. A infância, a pobreza e a experiência urbana. ComCiência: revista eletrônica de jornalismo científico. 2005. Disponível em: < http:// www.comciencia.br/reportagens/2005/12/11>.shtml. Acesso em: 18 jul. 2008.

GALLOWAY, Anne and WARD, Matthew. Locative Media as Socialising and Spatialising Practice: Learning from Archaeology. Leonardo Electronic Almanac, vol. 14, issue 3/4, 2006.

GRAHAM, S.; MARVIN, S. Telecommunications and the city: eletronics spaces, urban places. London: Routledge, 1997.

GUATARI, Félix. Caosmose: um novo paradigma estético. Rio de Janeiro: 34, 1992.

HARMON, K. You are here: personal geographies and other maps of the imagination. New York: Princeton Architectural Press, 2004.

HISSA, Cássio Eduardo Viana. Geografia e planejamento: entre o puro e 0 aplicado. Geonomos, Belo Horizonte, v. 6, n. 2, p. 33-43, 1998.

JACQUES, Paola Berenstein (org.). Apologia da deriva: escritos situacionistas sobre a cidade. Rio de Janeiro: Casa da Palavra, 2003.

JEUDY, Henri-Pierre. Espelho das cidades. Rio de Janeiro: Casa da Palavra, 2005.

JOSEPH, Isaac. El transeunte y el espacio urbano. Buenos Aires: Gedisa, 1988.
KOHAN, Martin. Zona Urbana: ensaios de lectura sobre Walter Benjamin.Buenos Aires: Norma, 2004.

KOSELECK, Reinhart. Futuros passados. Bertrand Brasil, 2007.

LEFEBVRE, Henri. 0 direito à cidade. São Paulo : Documentos, 1969.

Entrevista concedida à Kristen Ross em

1983. Disponível m: <http://www.rizoma.net/interna. php?id=138\&secao=potlatch $>$. Acesso em: 02 dez. 2008.

LEPETIT, Bernard. Por uma nova história urbana. Organização: Heliana Angotti Salgueiro. São Paulo: Edusp, 2001.

MASSEY, Doreen. Pelo espaço: uma nova política da espacialidade. Rio de Janeiro: Bertrand Brasil, 2008.

RONCAYOLO, Marcel. Cidade. In: ROMANO, Ruggiero (org.). Enciclopédia Einaudi. v.8. Lisboa: Imprensa Nacional-Casa da Moeda, 1986.

SANTOS, Milton. A natureza do espaço: técnica e tempo, razão e emoção. São Paulo: Hucitec, 1996.

SITUACIONISTA: teoria e prática da Revolução/ Internacional Situacionista. São Paulo: Conrad do Brasil, 2002. Coleção Baderna.

TARRIUS, Alain. Leer, describir, interpretar - las circulaciones migratorias: conveniencias de la noción de "territorio circulatorio". Los nuevos hábitos de la identidad. Relaciones 83, v. 21, verano 2000.

TELLES, Vera; CABANES, Robert. Nas tramas da cidade: trajetórias urbanas e seus territórios. São Paulo: Humanitas, 2006.

WEST, N. Urban Tapestries: The Spatial and the Social on your Mobile. Proboscis Cultural Snapshots. n. 10, jan. 2005. Disponível em: <http:// proboscis.org.uk/publications/SNAPSHOTS spatialandsocial.pdf>. Acesso em: 18 maio 2008. 


\section{Memory devices and urban space narratives: floating cartographies in time and space}

\section{Abstract}

This paper discusses the possibilities of reading urban space from common people's communicative interaction downtown, city of Belo Horizonte. For this study, we tried to understand the subject's action on the city's timespace as communicative interaction. By acting over the places, on daily life, a subject attributes meaning to space, transforming its sense or just updating its current meaning. The research data used as base on this study, was collected as cartographic drifts, a strategy of enquiring urban spaces inspired by situationists' leeway.

\section{Keywords}

Communicative interactions. City.

Urban territories.

\section{Dispositivos de memoria y narrativas del espacio urbano: cartografías flotantes en el tiempo y espacio}

\section{Resumen}

Este texto discute las posibilidades de lectura del espacio urbano a partir de la interacción comunicativa de personas comunes en las calles del Hipercentro de la ciudad de Belo Horizonte. Para estudiar este fenómeno, intentamos entender la acción de los sujetos sobre el espacio-tiempo de la ciudad como interacciones comunicativas. Cuando actúa por sobre los espacios, en el cotidiano, un sujeto atribuye significado al espacio, transformando su sentido o simplemente actualizando su sentido corriente. El material empírico de la investigación, que sirvió de base al estudio fue recogido por medio de derivas cartográficas, estrategia de abordaje del espacio urbano inspirado en las derivas situacionistas.

\section{Palabras clave}

Interacciones comunicativas. Ciudad.

Territorios urbanos. 


\section{Expediente}

A revista E-Compós é a publicação científica em formato eletrônico da Associação Nacional dos Programas de Pós-Graduação em Comunicação (Compós). Lançada em 2004, tem como principal finalidade difundir a produção acadêmica de pesquisadores da área de Comunicação, inseridos em instituições do Brasil e do exterior.
E-COMPÓS I www.e-compos.org.br I E-ISSN 1808-2599

Revista da Associação Nacional dos Programas de Pós-Graduação em Comunicação. Brasília, v.11, n.1, jan./abr. 2008.

A identificação das edições, a partir de 2008, passa a ser volume anual com três números.

\section{CONSELHO EDITORIAL}

\section{Afonso Albuquerque}

Universidade Federal Fluminense, Brasil

Alberto Carlos Augusto Klein

Universidade Estadual de Londrina, Brasi

Alex Fernando Teixeira Primo

Universidade Federal do Rio Grande do Sul, Brasi

Alfredo Vizeu

Universidade Federal de Pernambuco, Brasil

Ana Carolina Damboriarena Escosteguy

Pontifícia Universidade Católica do Rio Grande do Sul, Brasil

Ana Silvia Lopes Davi Médola

Universidade Estadual Paulista, Brasil

André Luiz Martins Lemos

Universidade Federal da Bahia, Brasil

Ângela Freire Prysthon

Universidade Federal de Pernambuco, Brasil

Antônio Fausto Neto

Universidade do Vale do Rio dos Sinos, Brasil

Antonio Carlos Hohlfeldt

Pontifícia Universidade Católica do Rio Grande do Sul, Brasil

Arlindo Ribeiro Machado

Universidade de São Paulo, Brasil

César Geraldo Guimarães

Universidade Federal de Minas Gerais, Brasi

Cristiane Freitas Gutfreind

Pontifícia Universidade Católica do Rio Grande do Sul, Brasil

Denilson Lopes

Universidade Federal do Rio de Janeiro, Brasil

Eduardo Peñuela Cañizal

Universidade Paulista, Brasil

Erick Felinto de Oliveira

Universidade do Estado do Rio de Janeiro, Brasil

Francisco Menezes Martins

Universidade Tuiuti do Paraná, Brasil

Gelson Santana

Universidade Anhembi/Morumbi, Brasil

Hector Ospina

Universidad de Manizales, Colômbia

leda Tucherman

Universidade Federal do Rio de Janeiro, Brasil

Itania Maria Mota Gomes

Universidade Federal da Bahia, Brasil

Janice Caiafa

Universidade Federal do Rio de Janeiro, Brasil

Jeder Silveira Janotti Junior

Universidade Federal da Bahia, Brasil
John DH Downing

University of Texas at Austin, Estados Unidos

José Luiz Aidar Prado

Pontifícia Universidade Católica de São Paulo, Brasil

José Luiz Warren Jardim Gomes Braga

Universidade do Vale do Rio dos Sinos, Brasi

Juremir Machado da Silva

Pontifícia Universidade Católica do Rio Grande do Sul, Brasil

Lorraine Leu

University of Bristol, Grã-Bretanha

Luiz Claudio Martino

Universidade de Brasília, Brasil

Maria Immacolata Vassallo de Lopes

Universidade de São Paulo, Brasil

Maria Lucia Santaella

Pontifícia Universidade Católica de São Paulo, Brasil

Mauro Pereira Porto

Tulane University, Estados Unidos

Muniz Sodre de Araujo Cabral

Universidade Federal do Rio de Janeiro, Brasil

Nilda Aparecida Jacks

Universidade Federal do Rio Grande do Sul, Brasil

Paulo Roberto Gibaldi Vaz

Universidade Federal do Rio de Janeiro, Brasil

Renato Cordeiro Gomes

Pontifícia Universidade Católica do Rio de Janeiro, Brasil

Ronaldo George Helal

Universidade do Estado do Rio de Janeiro, Brasil

Rosana de Lima Soares

Universidade de São Paulo, Brasil

Rossana Reguillo

Instituto Tecnológico y de Estudios Superiores do Occidente, México

Rousiley Celi Moreira Maia

Universidade Federal de Minas Gerais, Brasil

Sebastião Carlos de Morais Squirra

Universidade Metodista de São Paulo, Brasil

Simone Maria Andrade Pereira de Sá

Universidade Federal Fluminense, Brasil

Suzete Venturelli

Universidade de Brasília, Brasil

Valério Cruz Brittos

Universidade do Vale do Rio dos Sinos, Brasil

Veneza Mayora Ronsini

Universidade Federal de Santa Maria, Brasil

Vera Regina Veiga França

Universidade Federal de Minas Gerais, Brasil

\section{COMISSÃO EDITORIAL}

Ana Gruszynski I Universidade Federal do Rio Grande do Sul, Brasil João Freire Filho I Universidade Federal do Rio de Janeiro, Brasil Rose Melo Rocha I Escola Superior de Propaganda e Marketing, Brasil

\section{CONSULTORES AD HOC}

Bianca Freire-Medeiros I Fundação Getulio Vargas, Brasil Josimey Costa da Silva I Universidade Federal do Rio Grande do Norte, Brasil Maria Conceição Golobovante I Pontifícia Universidade Católica de São Paulo, Brasil Marlyvan Moraes de Alencar I Centro Universitário SENAC-SP, Brasil Miriam de Souza Rossini I Universidade Federal do Rio Grande do Sul, Brasil Paulo Ribeiro I Pontifícia Universidade Católica do Rio de Janeiro, Brasil Rita Alves de Oliveira I Centro Universitário SENAC, Brasil

REVISÃO DE TEXTO E TRADUÇÃO I Everton Cardoso ASSISTÊNCIA EDITORIAL E EDITORAÇÃO ELETRÔNICA I Raquel Castedo
COMPóS I www.compos.org.br

Associação Nacional dos Programas de Pós-Graduação em Comunicação

Presidente

Erick Felinto de Oliveira

Universidade do Estado do Rio de Janeiro, Brasil erickfelinto@uol.com.br

Vice-presidente

Ana Silvia Lopes Davi Médola

Universidade Estadual Paulista, Brasil

asilvia@faac.unesp.br

Secretária-Geral

Denize Correa Araújo

Universidade Tuiuti do Paraná, Brasil

denizearaujo@hotmail.com 